South African Journal of Geomatics, Vol. 5. No. 2, September 2016

\title{
Evaluating a Public Sector Organisation for SDI Readiness - The Case of a South African Government Department
}

\author{
Sibusisiwe Hlela ${ }^{1}$, Serena Coetzee ${ }^{2}$ and Antony Cooper ${ }^{3}$ \\ ${ }^{1}$ Centre for Geoinformation Science, University of Pretoria, Pretoria, South Africa, \\ sbuhlela1@gmail.com \\ ${ }^{2}$ Centre for Geoinformation Science, University of Pretoria, Pretoria, South Africa \\ ${ }^{3}$ Built Environment Unit, CSIR, Pretoria, South Africa
}

http://dx.doi.org/10.4314/sajg.v5i2.1

\begin{abstract}
Spatial data infrastructure (SDI) facilitates the collection and sharing of geographic information developed by different organisations. As a result, SDI initiatives are occurring in different countries. Various government departments are implementing SDI in order to contribute to the achievements of its objectives. SDI assessments to evaluate the implementation thereof is also occurring from local levels to international levels. This paper establishes the availability of geographic information within the Department of Environmental Affairs (DEA) by describing $D E A$ 's contribution to the South African SDI objectives and by assessing DEA's SDI readiness.

The qualitative method was used to collect data. The techniques used in this research were literature review, interviews, mainly in-depth interview, document and internet analysis.

The results indicate that geographic information is available and the department continues to make more means to make it available. They also reveal that there are some challenges with respect to accessibility. Currently there is a process to make it even more easily accessible. The results show DEA's willingness and capacity to contribute to the South African SDI. The voluntary participation in SDI activities and the ability to obtain additional funding for geographic information is a clear indicator of DEA's willingness to contribute to SASDI's objectives. The results contribute to the body of knowledge that if an SDI is still in the early stages of development, it is challenging to make conclusions on some of the key SDI assessment indices. Future research is required once South African SDI has reached mature stages.
\end{abstract}




\section{Introduction}

Geographic information is defined as 'information concerning phenomena implicitly or explicitly associated with a location relative to the Earth.' (www.iso.org/obp/ui/). Information, including geographic information, is shared or needs to be shared comprehensively amongst stakeholders in order to make informed decisions (Pearlson \& Saunders, 2013; Harvey \& Tulloch, 2006). Private and public sectors both need information in order to make informed decisions. This research focuses on the public sector.

Government needs geographic information in order to make informed decisions on a variety of issues such as poverty, unemployment, climate change, use of natural resources, protected areas and provision of infrastructure. A number of authors associate comprehensive utilisation of information systems, including geographic information systems (GIS), with economic growth (Babinski, 2012; Makanga and Smit, 2010; Du Plessis, 2007; Kok and Van Loenen, 2005; Maguire and Longley, 2005; Masser, Campbell and Craglia, 1996; Smith and Tomlinson, 1992).

The DEA needs to make informed decisions about environmental management. It requires geographic information which might be available from other organisations.

SDI facilitates access and sharing of geographic information beyond the confines of a single organisation (Okuku et al., 2014). The SDI initiatives, worldwide have emerged as a result of the growing necessity to share geographic information beyond the boundaries of one organisation or, a country (Hjelmager et al., 2008).

The availability of geographic information in an organisation is important. For this reason, the availability of geographic information within DEA has to be established. In the context of this research, availability refers to what geographic information is available, how accessible it is to the end users and how it is shared.

The availability of geographic information $n$ within DEA is assessed by describing DEA's contribution to the SASDI objectives and by assessing DEA's SDI readiness. The remainder of the paper is organised as follows. Section 2 provides background on spatial data infrastructures and their assessment. Section 3 describes the research techniques used for this paper. Section 4 describes DEA's contribution to SASDI objectives and Section 5 provides a qualitative assessment of DEA's SDI readiness. Section 6 concludes. 


\section{Background}

\subsection{SDI Objectives and the Rationale for SDI Assessment}

The US National Research Council came up with the term spatial data infrastructure in 1993 (Mapping Sciences Committee, 1993). However the concept of providing or having larger access to geographic information was conceived in the 1980s (Groot and McLaughlin, 2003; Rajabifard and Feeney, 2003). The SDI concept is broad and incorporates various forms of geographic information (Hjelmager et al., 2008).

Literature (Coetzee and Wolf-Piggott, 2015; Okuku et al., 2014; Harvey et al., 2012, Hendriks et al., 2012; Hjelmager, 2008) reveal that SDI concept is broad and evolves over time hence different authors define it in different ways. Hendriks et al., (2012) has done detailed work focusing on the definitions of SDI. There are numerous definitions for SDI, some describe it from a component viewpoint and others from an SDI objective viewpoint as indicated in Table 1 below.

Table 1: Different types of SDI definitions adapted from Hendriks et al., 2012

\begin{tabular}{|l|l|}
\hline Component viewpoint & Objective viewpoint \\
\hline The components of spatial data infrastructure should & Spatial Data infrastructure is about the facilitation and \\
include sources of spatial data, databases and metadata, \\
data networks and technology, institutional \\
coordination of the exchange and sharing of the spatial \\
data between stakeholders in the spatial data community \\
(McLaughts, policies and standards, and end-users & (Fernandez et al., 2004, Rajabifard et al., 2002) \\
\hline
\end{tabular}

Countries at international level have realised SDI is an 'indispensable infrastructure' (Makanga and Smit, 2010:18) in terms of facilitating accessibility and sharing of geographic information such that there are now formal bodies managing the implementation of SDI initiatives. In Europe there is Infrastructure for Spatial Information (INSPIRE) and in USA there is Federal Geographic Data Committee. In Africa there is no formal body yet, that manages the implementation of SDI initiatives.

As much as there is no formal structure at a continental level in Africa, work is happening at an individual country level. Organisations that are involved in collecting core base data sets have realised the importance of working together in order to reduce duplication in the collection of geographic information and to also allow for easier access and sharing of information (Makanga and Smit, 2010).

The South African SDI (SASDI) is established through the South African Spatial Data Infrastructure Act No. 54 of 2003 as a national technical structure to facilitate the capturing, management, maintenance, integration, dissemination and use of geographic information (South African Spatial Data Infrastructure Act No. 54 of 2003, s3 (1). 
The analysis of the definitions makes it clear that the rationale behind SDI is to ensure that geographic information is accessible to all the users. The management of it should happen in a controlled manner as now at the regional level there are bodies that are overseeing the implementation. The SDI came about as a result of trying to control the duplication of efforts in the collection of data. Again the importance of management of geographic information will oversee that duplication is controlled. The control in the duplication of data collection will also save money that is spent in collecting data. The management of SDI also ensures that instead of duplicating the collection of data, organisations share what they have. But moreover, there must be clear agreement in terms of data custodianship. It is against this background that SDI assessments have started so as to review the implementation of such good objectives.

\subsection{SDI Assessment Methods}

As a result of the importance of SDI, a number of assessments have been done to follow up on the progress of these initiatives. Literature (Okuku et al., 2014; Fernandez et al., 2008; Hjelmager et al., 2008, Hendriks, 2012) reveal that SDIs are multi-faceted in nature. They are transformational and established in an endless negotiation situation. This is also the case with SASDI, as some of the issues or strategic direction on the objectives has not yet been concluded. As a result of the multifaceted nature of SDIs, multi-view approach assessment methods are used. SDI assessment have been done at various levels, that is, global, regional, national (one country), sub-national (incorporates more than one local authority, province, federal states) and local municipality. SDI assessments have also been done according to geographic areas. Others according to SDI domain, for example, coastal zone, wetlands, disaster management (Coetzee and Wolff-Piggott, 2015; Idrees, 2015; Okuku et al., 2014; Makanga \& Smit, 2010; Harvey et al., 2012; Mansourian et al., 2006; Georgiadou et al., 2005; Rajabifard, 2003; Mapping Science Committee, 1993).

Multi-view assessment framework includes nine different assessment approaches. Four of them are applicable and these are SDI readiness, organisational, clearinghouse suitability and state of play. The other five need improvement and these are cadastral, performance based, user's perspective, metaphorical and legal.

In this paper, the SDI readiness approach will be used to assess the availability of geographic information at DEA. The purpose of the SDI readiness assessment approach is to ascertain the readiness of the country with respect to SDI development. This is done by analysing the willingness and capacity of the country. SDI readiness is used as a monitoring tool to assess the development and circumstances of the country if they are contributing to SDI development. It analyses or ascertains obstacles in SDI programme implementation. This is done by looking at the 
strengths and weakness of the environment where SDI develops. SDI Readiness as a monitoring tool also assists in raising awareness with respect to the realistic basis for the success of SDI (Fernandez et al., 2008).

Studies done in 127 countries indicate that the sustainability of SDI depends on the balance of these factors, that is, technology, organisational and social factors. In the studies done, it shows that organisational factor which includes human and financial factors is the key for the success of SDI developments. Hence SDI readiness is done by using five indexes, organisational, information, human resources (people), technology (access network) and financial resources (Fernandez, et al., 2008). The indexes have a similar concept to what Makanga \& Smit, (2010) call indicators. These indices or indicators provide an indication of the potential of the country to contribute to SDI. SDI assessment approaches can be applied at local level, that is, within an organisation or municipality to global level. In this study, the SDI assessment is done at an organisational level.

The challenges with SDI assessment is that SDI is still in the evaluation stage, as a result it is a challenge to collect reliable and complete data about some of the reports (Fernandez et al, 2008). This is the case with the South African SDI which then impacted on the collection of information for this paper. Harvey et al, (2012) states that SASDI was enacted in 2003 but CSI members were only appointed in 2010.

\section{Method}

The availability of geographic information within DEA is assessed by describing DEA's contribution to the SASDI objectives and by assessing DEA's SDI readiness. In the context of this research, availability refers to what spatial information is available and whether it is accessible to the end-users.

Non-probability sampling techniques such as convenience samples, snowball samples, and purposive samples were used for interviews. Experience has shown that it is hardly ever possible to involve the target or sampling population, which is DEA and mainly the GIS personnel, in the research. Therefore the sampling frame for this research will be influenced by the accessibility of participants (Kumar, 2011).

Purposive or judgemental sampling happens when a researcher selects a sample of participants who conform or comply with 'some criterion' (Blumberg et al., 2008:253). Purposive sampling was choosen in this research because it allows flexibility and openness. It forms part of the loose research design which has the benefit of allowing the sampling to be designed based on the progress of the research (Flick, 2007). It also allows the researcher to make a judgement decision about who has the best information. It allows for information to be collected until it gets 
to what is called a 'saturation point' (Kumar, 2011:208). This was the case with this research as an in-depth interview was conducted with the most senior official in the geographical information unit of the department. The most senior official then referred the researcher to another official who also had important information.

The techniques used in this research were literature review, in-depth interview, and document and internet analysis. Literature review was used to analyse previous research work on SDIs and SDI assessment approaches and case studies. In-depth interview has proven to be an invaluable source of information in the writing of this paper. The first author was the primary instrument for data collection. Analysis of some documents was also done as another form of data collection, especially for the analysis of the application of SASDI within the organisation. Internet search was conducted to verify the availability of geographic information and its accessibility.

\section{Results: DEA's Contribution to the SASDI Objectives}

\subsection{Background}

Makanga and Smit (2010) in the review of SDI development in Africa observed that in Africa there is a lagging of formal SDI but there are lot of informal activities which then lead to a formal SDI, which is also the case with South Africa. SASDI was established through the Act of Parliament, the South African Spatial Infrastructure Spatial Act in 2003. Harvey et al., (2012) state that formal efforts started in 1997 by the establishment of the National Spatial Information Framework Directorate in the Department of Land Affairs. Prior to that a couple of informal activities occurred. There was an informal structure called GIS User Group from 1992 up to 1996 (Pretorius, personal communication, March 2016). Harvey et al., (2012) also point out that some work done in the 1990s is a clear indicator of the conception of SDI in South Africa, that is, the coordination by the stakeholder government departments of the contract for aerial photography to avoid duplication and to promote sharing of geographic information.

The Act establishes the Committee for Spatial Information (CSI). CSI has the responsibility to provide strategic direction on a number of issues with respect to the implementation of SASDI in South Africa. The CSI committee and its sub-committees are also in the process of developing the data custodianship policy and pricing policy. All of these plans are awaiting the approval of the relevant political head (CSI, 2013). 


\subsection{Base Data Sets}

There are many terms and definitions for the base data. Global Spatial Data Infrastructure (2004) lists other terms for base data sets such as core, reference, and base fundamental data. Schwabe and Govender (2012:16) use the terms fundamental data set or core data sets interchangeably and define it as follows

'Fundamental datasets are the minimum primary sets of data that cannot be derived from other datasets, and that are required to spatially represent phenomena, objects, or themes important for the realisation of economic, social, and environmental benefits consistently across Africa at the local, national, sub-regional and regional levels'.

According to SASDI Act, base data sets 'means those themes of spatial information which have been captured or collected by a data custodian' (RSA, 2003). To date, much work has been done in terms of defining the criteria, identifying base data sets or what Schwabe and Govender (2012) call core data sets and custodians in SASDI.

DEA has been identified or proposed as the custodian for core geospatial datasets, such as environmentally sensitive areas, coastlines and bioregions (Schwabe \& Govender, 2012).

DEA obtains geographic information either by buying or obtaining it free of charge from some organisations. Geographic information from other government departments, some agencies and parastatals is obtained free of charge. Some agencies provide data at a cost, for example Geoscience Council. Funding models for organisations developing geographic information has got an impact on whether the data is purchased or obtained free of charge (Pretorius, personal communication, March 2016). Some of the geographic information is purchased from private companies if there is more value than the one from a government organisation which is available free of charge. For example, in a case where in addition to cadastral information, a private company provides more geographic information as a package including roads, houses, monuments, etc. DEA purchases from the private company (Pretorius, personal communication, March 2016).

\subsection{Dissemination of Geographic Information}

All of the above geographic information is disseminated using various methods such as internet, memory sticks, DVDs, printable maps and hard copies, depending on the size of the data. For example the huge land cover data sets $47 \mathrm{~GB}$ were given to end-users via the memory sticks. It has proven hard to access huge amounts data sets $47 \mathrm{~GB}$ via the internet because of the length of time it takes to download. Hard copies are provided for those maps produced many years ago which have never been digitised. But it is not often that hard copies are done. 
The latest development in terms of making data accessible as widely as possible is that the DEA is now developing a geoportal. The geoportal will allow DEA to provide access to different types of end-users. It will also allow users to do a search for particular spatial data. Portal will also enable access to geographic information even on mobile devices such as ipads, cellphone and laptops.

\subsection{Policies}

According to the CSI Annual Report, 2012/2013 the Policy and Legislation sub-committee has drafted the custodianship policy and the policy for the pricing of spatial information products and services. However, these policies are still in draft form (Fourie, personal communication, March 2016). Therefore one is not in a position to say how DEA is contributing to the achievement of SASDI objectives in this area.

\section{Results: DEA's SDI Readiness}

\subsection{Organisational Assessment}

The organisation index includes politicians, SDI vision, and institutional leaders and legal framework. Schwabe \& Govender (2012) have done analyses of legislation in the country regarding core dataset. The findings of the study indicate that legislation is not explicit on spatial function and custodianship. However legislation is amended from time to time, functions and custodianship could be clarified by further legislative amendments.

\subsection{Information Assessment}

It has been explained above that DEA has geographic information. Where it is not available, efforts are done to obtain it either free of charge or purchase if necessary. DEA is now developing the geoportal.

\subsection{Human Resources Assessment}

Human index focuses on the human capital index, culture/ education as well as awareness on SDI and individual leadership. The findings of the survey of the South African GISc community reveal, among other things, that $40 \%$ of GISc community have got formal qualifications, at least Honours degree or equivalent and are also under 40 years. However $26 \%$ of respondents have qualifications that do not meet the core competencies of the professional registration body, the South African Council for Professional and Technical Surveyor (PLATO) (Coetzee, 2014). The availability of competent people is key for SASDI development. The majority of personnel in DEA 
is around the age of 40 and they have formal qualifications. This presents an opportunity for DEA to address the required competencies.

The people aspect, competency issues and the role of leadership are going to be the main subjects of the second paper hence not much detail about this index in this first paper. However, with respect to awareness as part of this human index, DEA contributes conducting GIS Open Days for two days annually where organisations countrywide are invited to attend. This is where DEA updates stakeholders about the latest developments about geographic information issues.

\subsection{Financial Assessment}

The financial index focuses on the availability of funds for SDI objectives. Inadequate funds hamper the progress of SDI. This is also not peculiar to this organisation DEA. However, all endeavours are done to obtain crucial geographic information. For example, EGIM will source funds from other units which spent less from their funds before the end of the financial year and then use those funds to purchase more geographic information.

Funding remains a key factor in purchasing geographic information as well as in funding the development of spatial data infrastructure. It is good that the EGIM is doing the best they can to get more funding.

\subsection{Technology Assessment}

Technology index includes web connectivity and open source software. The geographic information is also made available via internet access. However, experience has shown downloading huge amounts of data is a challenge. For example the land cover data set of $47 \mathrm{~GB}$. DEA has moved into Enterprise Software licence.

As SDI Readiness also monitors strengths and weakness of the environment in which SDI development happens, the accessibility of large amounts such as 47GB of data seems to be a weakness in the system. There needs to be a way of making sure that even large volumes of data are accessible via the internet within a reasonable amount of time.

\subsection{Summary of the Assessment}

The section summarises the assessment of DEA based on the SDI Readiness assessment indices. Table 2 below provides the summary. 
Table 2: Summary of the assessment

\begin{tabular}{|c|c|}
\hline Index & Summary of assessment \\
\hline Organisational assessment & $\begin{array}{l}\text { In order to gain support of senior officials or political powers, there is a } \\
\text { need to continue presenting tangible benefits (Makanga and Smit, 2010). } \\
\text { As SDI happens in the environments that transforms over time, there is } \\
\text { a need to evaluate legislation again. }\end{array}$ \\
\hline Information assessment & $\begin{array}{l}\text { In terms of SDI readiness assessment, the availability of geographic } \\
\text { information is one of the strengths of this organisation. DEA is also in } \\
\text { the process of making it more available via the internet. }\end{array}$ \\
\hline Human resources assessment & $\begin{array}{l}\text { The majority of personnel in DEA is around the age of } 40 \text { and they } \\
\text { have formal qualifications. This presents an opportunity for DEA to } \\
\text { address the required competencies. The voluntary participation in the } \\
\text { CSI sub-committees and the ability of the EGIM unit to do everything } \\
\text { in their power to obtain funding for geographic information is clear } \\
\text { indicator of DEA's willingness to contribute to SASDI's objectives. }\end{array}$ \\
\hline Financial assessment & $\begin{array}{l}\text { Funding remains a key factor in funding the development of spatial } \\
\text { data infrastructure. It is good that the EGIM is doing the best they can } \\
\text { to get more funding. In order to gain more financial support, it is } \\
\text { crucial for DEA to speak the language that Treasury speaks. Basically } \\
\text { provide tangible benefits from geographic information and spatial data } \\
\text { infrastructure }\end{array}$ \\
\hline Technology assessment & $\begin{array}{l}\text { DEA is on a positive path as there are now discussions about geoportal } \\
\text { which will make geographic accessible even on mobile devices. }\end{array}$ \\
\hline
\end{tabular}

\section{Conclusion}

The value of accessing and sharing geographic information is acknowledged worldwide. The SDI is the vehicle that facilitates the accessibility, sharing and reduce duplications in the collection of geographic information. Many countries, as a result have done assessment to review the implementation of SDIs. The SDI implementation has its own challenges which are identified through the assessments undertaken. One of the challenges about assessing SDI is that most SDIs are still young and moreover, evolutionary in nature. This does impact on the collection of information and making conclusive statements on the organisations' contribution on some of the SASDI objectives. It is therefore recommended that future research on the SDI assessments should be done. For example, the legal framework index will need to be assessed again in the future because legislation also gets amended from time to time.

Geographic information is available, the infrastructure is available. DEA has done a lot of work to implement the SASDI objectives, especially to provide invaluable geographic information. This is not to say that all aspects of SASDI are functioning smoothly but commendable effort has been done, especially in the area of ensuring that geographic information is available. DEA continues to develop new methods of ensuring access and ease of availability to geographic information, as the organisation is now working on developing the geoportal. It is up to the end- 
users to make sure that they use this invaluable geographic information to make informed decisions. The second paper will then focus on the use of geographic information in DEA.

This paper has reviewed DEA's contribution to SASDI objectives using SDI readiness assessment approach as one of the multi-review assessment approaches. The results of the study show that DEA continues to do everything possible to make geographic information easily accessible to the users. Although there is a challenge with respect to downloading time for huge geographic information. Currently there is a process to develop geoportal which will make geographic information to be even easily accessible via mobile devices, such as ipads and cellphones.

In future work, we plan to assess the competency of DEA employees to use geographic information to its full potential. From this, the organisational competency of DEA will be assessed. The results of this assessment will be used to draw conclusions about DEA's competency to use geographic information for informed decision-making. Finally, a geographic information competency maturity model that focuses on people will be developed.

\section{References}

Babinski, G 2012. 'URISA develops the geospatial management competency model (GMCM) for USDOLETA', Washington GIS Conference 9 May 2012 Tacoma, Washington, viewed November 2012, <http://www.google.com>

Coetzee, S \& Wolff-Piggott, B 2015, 'A Review of SDI Literature: Searching for Signs of Inverse Infrastructures', Cartography-Maps Connecting the World, pp. 113-127. Springer International Publishing.

Coetzee, S, Eksteen, S \& Roos, A 2014, 'Results from a survey of the South Africa GISc community show who they are and what they do', South African Journal of Geomatics, vol.3 no.2, pp.224 - 245.

Committee for Spatial Information, 2011/2012, Annual Report, Department of Rural Development and Land Reform.

Committee for Spatial Information, 2012/2013, Annual Report, Department of Rural Development and Land Reform.

Du Plessis, H 2007, 'Outcome based qualifications for building intellectual capital in GISc to provide the foundation for sustainable development and poverty alleviation in Africa', Map Africa, Cape Town, Conference, Cape Town, South Africa, October 2012

Fernandez, TD, Fernandez, MD \& Andrade, RE 2008, 'The spatial data infrastructure readiness model and its worldwide application', In Crompvoets, A, Rajabifard, A, van Loenen, B \& Fernandez D (eds.), A Multi-View Assessment to assess SDIs. Space for Geo-Information, Wageningen University and Centre for SDIs and Land Administration, Department of Geomatics, University of Melbourne, Australia. 
Flick U. (2007) Designing Qualitative Research. SAGE Publications Ltd: London.

Georgiadou, Y, Puri, SK \& Sahay, S 2005 'Towards a potential research agenda to guide the Implementation of Spatial Data Infrastructures - A case study from India', International Journal of Geographical Information Science, vol.19, no.10, pp.1113-1130.

Global Spatial Data Infrastructure, 2004, Developing Spatial Data Infrastructures: SDI Cookbook, in Nebert DD (ed.), version 2.0.

Groot, R \& McLaughlin, J 2003, Geospatial Data Infrastructure: concepts cases and good practice. Burrough P A, Goodchild MF, McDonnell, Switzer, Worboys M (eds.), Oxford University Press, New York.

Harvey, F \& Tulloch, D 2006, 'Local-government data sharing: Evaluating the foundations of spatial data infrastructures', International Journal of Geographical Information Science, vol.20, no.7. pp. 743768.

Harvey, F, Iwaniak, A, Coetzee, S \& Antony, C 2012, 'SDI past, present and future: a review and status assessment', Spatially Enabling Government Industry And Citizens, pp.23 - 38.

Hjelmager, J, Moellering, H, Cooper A, Delgado T, Rajabifard, A, Rapant, P, Danko, D, Huet, M, Laurent D, Aalders, H, Iwanaiak A, Abad P, Duren U \& Martynenko, A 2008, A Geographical Information Science, vol. 22, no. 11 - 12, pp,1295 - 1309.

Hendriks, PHJ, Dessers, E \& van Hoorten, G 2012, 'Reconsidering the definition of a spatial data infrastructure', International Journal of Geographical Information Science, vol.26, no.8, pp.1479 -1494 .

Idrees, M 2015, Challenges in coastal spatial data infrastructure implementation: A review. South African Journal of Geomatics. vol.4 no.4 pp.369-383.

ISO 19101 -1:2014<www.iso.org/obp/ui/>

Kok, B \& van Loenen, B 2005, 'How to assess the success of natural spatial data infrastructures', Computers, Environment and Urban Systems, vol.29, pp.699-717.

Kumar, R. 2011 Research Methodology a Step-by-step Guide for Beginners. SAGE Publications: London.

Maguire, D \& Longley, P 2005. 'The emergence of geoportals and their role in spatial data infrastructures', Computers, Environment and Urban Systems vol.29, pp.3-14.

Makanga, P \& Smit, J 2010, 'A review of the status of the Spatial Data Infrastructure in Africa'. University of Cape Town, South African Computer Journal no.45, pp-18-25.

Mansourian, A, Rajabifard, A, Zoej, MJV \& Willianson I, 2006, 'Using SDI and web-based system to facilitate disaster management', Computers and Geosciences, vol.32, pp.303-315. 
Mapping Sciences Committee, 1993, Towards a coordinated spatial data infrastructure for the nation, National Academy Press, Washington, DC.

Masser, I Campbell, H. \& Craglia, M 1996, GIS diffusion: The adoption and use of geographical information systems in Local Government in Europe, Taylor and Francis, UK.

Okuku, J, Bregt A \& Grus, L 2014, 'Assessing the development for Kenya National Spatial Development Infrastructure', South African Journal of Geomatics, vol.3 no.1, pp 95-112.

Smith, DA \& Tomlinson, RF 1992, Assessing costs and benefits of geographical information systems: Methodological and implementation issues, International Journal of Geographical Information Systems, vol. 6, no.3, pp.247-276.

Pearlson, KE \& Saunders, CC 2013, Strategic management of information systems, John Wiley \& Sons, Singapore.

Rajabifard, A, Feeney, MF, Williamson, IP 2002, 'Future directions for SDI development', International Journal of Applied Earth Observation and Geoinformation, vol. 4, pp.11-22.

Republic of South Africa, 2003. South African Spatial Data Infrastructure Act No.54 of 2003, Government Gazette, No.113, 04 February 2004.

Schwabe, C \& Govender S, 2012, Stakeholder survey on defining the criteria and identifying core geospatial datasets and data custodians in South Africa, South Africa. 